\title{
THE RETINAL VISUAL CELLS IN MAN AND FRESH-WATER FISH
}

BY

\author{
M. S. MAYOU \\ LON DON
}

WHILST trying to discover some differential stain for the rods and cones I found that Mallory's connective tissue stain has a more or less selective action on certain cells in the retina. In the human retina the red acid fuchsin stains strongly the cones and the cone nuclei (if carefully decolourised) in the outer nuclear layer; it also stains the rods but not the rod nuclei and in this I think that we may have a means of recognising the difference between a rod and a cone, a thing which is not at all easy to do especially in the macular region of the human retina. Apart from this the stain gives such excellent definition of the visual cell layer that it has led me to re-investigate these cells in some fresh-water fish. I showed the first microscope sections at the meeting of the Ophthalmological Society of the United Kingdom in 1932.

An enormous amount of work has been done on the subject by different observers and the amphibia have been very carefully studied, but any observer who undertakes investigation on this subject has to be careful not to drop into the numerous pitfalls with which the subject is surrounded, which have led to the chaotic condition in which the subject is at the present time. The fish which I have examined are pike, dace, roach and trout, and except for the first-named they have received little attention, which is also one of the excuses for this paper. Owing to the kindness of Prof. Gladstone I have had an opportunity of examining the collection of specimens made by H. M. Bernard illustrating the visual cells in amphibia and the lower vertebrate retinae with their development.

The theory of vision which is now most usually accepted and known as the duplicity theory, in which the cones are supposed to be associated with form and colour vision and the rods with the light sense, is by no means proved. L. B. Airey's remarks on the theories of function of the rods and cones are very apt and he says " it is doubtlessly true that many such experiments reveal the resourcefulness of the human mind rather than the ingenuity of nature, yet a suggestive and stimulating hypothesis serves its purpose if only the possible dynamic inter-relations of parts are thereby brought to light."

One of the objects of this paper is to draw attention to the physical side of the formation of the rods and cones which, in fish, are not differentiated as they are in man. 
The phylogenetic development of the visual cells is difficult to follow in that they depend to a certain extent on the environment of the animal.

The changes consist in (1) differentiation of an area of hypersensitiveness (macula). (2) the gradual development of a higher type of retina with alteration and increased number of visual cells composing it and finally the differentiation into two different types of cells, namely, rods and cones.

(1) The development of a macula or a specially sensitized area of the retina, is essentially dependent on the environment of the animal, since it is found as low down in the scale as the reptiles which are, to a large extent, dependent on the visual acuity for food, but is absent in animals such as the dog whose sense of smell is the more important factor. The macula does not re-appear in the animal scale until the monkeys are reached.

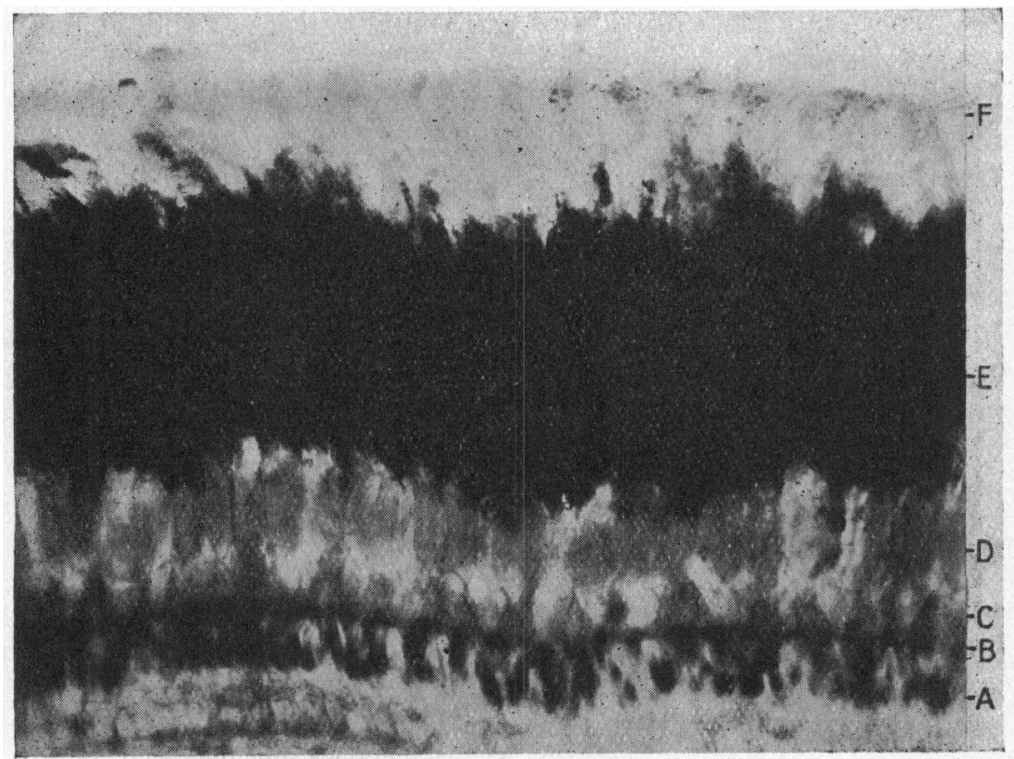

Fig. 1. Pike, Retina.

Light adapted, showing the inward movement of the pigment.

Retina showing the visual cells (unbleached section).

A. External nuclear layer.

B. External limiting membrane.

C. Myoid of visual cells.

D. Ellipsoid.

E. Pigment concealing the outer members of the cell.

F. Retinal pigment cells nuclei. 
(2) The development of the higher types of retina which contain rods and cones comes, in a much more gradual manner and depends not only on the requirements of the animal for the sense of light and movement with better visual acuity, form and colour sense, but also upon the gradual anatomical development of the whole eye. It is these changes in the anatomical appearance of the visual cells that I wish to draw attention to, by contrasting the difference between the visual cells of fresh-water fish and man.

The movement of the pigment cells in fish was discovered by Stort in 1884, and has been extensively investigated by Kuhne and later by Detwiler ${ }^{1}$ and Airey. ${ }^{2}$

Under the influence of light the pigment moves inward within the cells leaving the nucleus lying on the membrane of Bruch which is easily seen and quite free of all pigment (Fig. 1). The pigment is densest around the apices of the ellipsoid which in the state of light adaptation are retracted inwards. The outer members of the visual cells are completely surrounded with dense black pigment. This pigment is composed of fine granules and is best seen in tangential sections of the retina. When one looks at the fundus of a fish, such as a pike, one sees a number of bright points surrounded by dark pigment. The bright points are of the same colour as the silvery layer in the iris and are undoubtedly produced by light reflected from the silvery layer in the choroid being transmitted forward through the pigment by the outer members of the visual cells. ${ }^{3}$

In dark adaptation the pigment granules in the cells move outwards towards the membrane of Bruch; this is associated with the outward movement of the ellipsoid and must necessarily be also associated with a certain amount of outward movement in the pigment cells themselves. Droplets are said to form on the rods which are supposed, by Detwiler, ${ }^{4}$ to be the visual purple.

In light adaptation the reverse takes place, the pigment moving inwards within the cells and striations is said to appear in the rods.

It is not only light which will cause movement in the ellipsoid and pigment cells. It has been shown by Airey and Detwiler that heat has a similar effect, the myoid being elongated at high temperatures. On the other hand the movements of the pigment cells and ellipsoid can be dissociated as shown by Airey in that the division of the optic nerve causes the movement in the ellipsoid to cease, but the movement of the pigment is not affected.

\section{The Visual Cells}

Microscopical anatomy (Fig 2).- The structure of the visual cells is much more easy to recognize in fish on account of their large size than in the human retina, but so far the movements of the cells 
VISUAL CELL

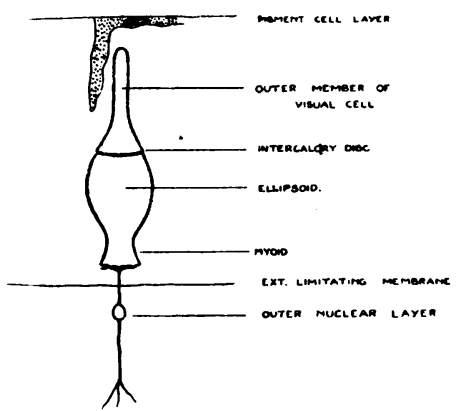

FIG. 2.

Diagram showing the anatomy of the visual cells.

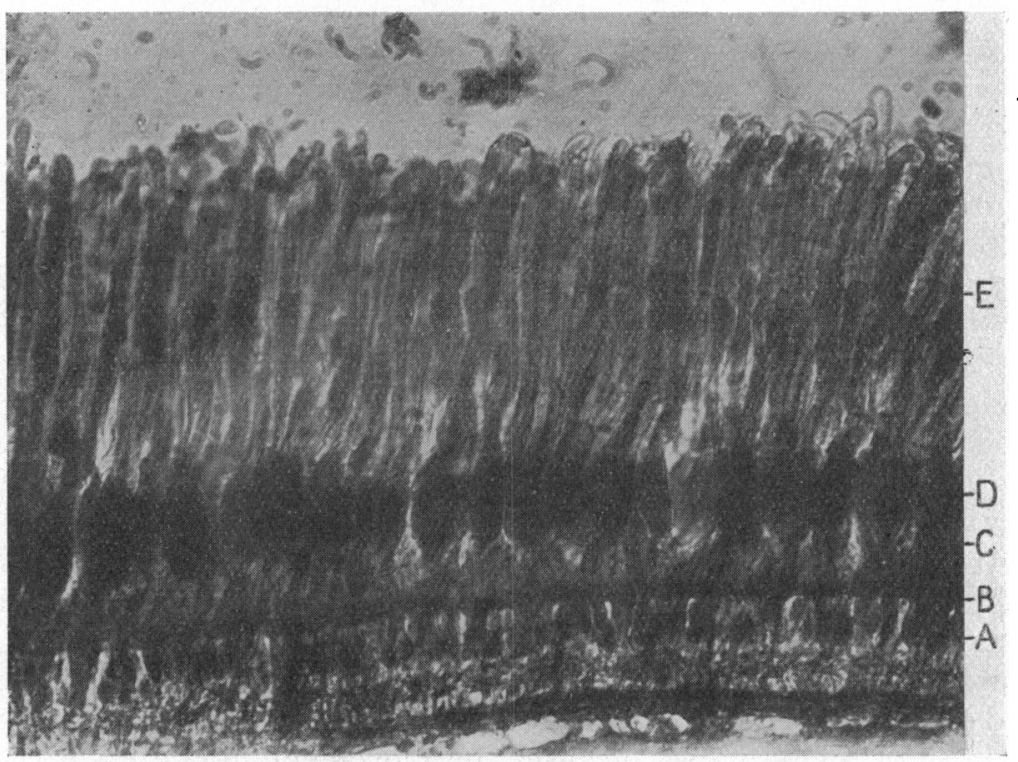

Fig. 3. Pike. (Bleached. Mallory.)

Light adaptation, retina showing the visual cells (bleached section).

A. External nuclear layer

B. External limiting membrane.

c. Myoid.

D. Ellipsoid.

E. Outer member of the visual cell (rods). 
present in fish have not been demonstrated in the visual cells of the human retina, although it is possible that it may occur.

The visual cells lie on either side of the external limiting membrane. The nucleus which forms the outer nuclear layer lies on the inner side of the external limiting membrane, whilst the main part of the visual cell lies on the outer side. They are connected together with protoplasmic strands which pass through the external limiting membrane, through which they have originally grown during development.

The part of the visual cell which lies external to the limiting membrane consists of a portion which lies next to the membrane which is known as the myoid, and it is this portion of the cell which becomes elongated when the ellipsoid moves outwards under the influence of dark adaptation. Next to this is a cone-shaped and more expanded portion of the cell known as the ellipsoid; both the myoid and ellipsoid stain strongly red with fuchsin in the Mallory stain. Between the ellipsoid and the outer member of the cell is some cytoplasm which does not take the stain in ordinary methods and this is known as the intercalary disc. The outer member which is narrowed and is only about half the diameter of the ellipsoid, stains a yellowish colour with Mallory stain and lies in direct contact with the pigment cells of the pigment layer which interdigitate with them. In fish under the influence of light there is a marked movement both of the pigment and of a portion of the visual cells external to the limiting membrane (Fig. 3, 4 and 5).

Histology. - The histology of the visual cells is surrounded with considerable difficulties; first of all fixation of any kind must produce changes in the cells which will alter them from their natural

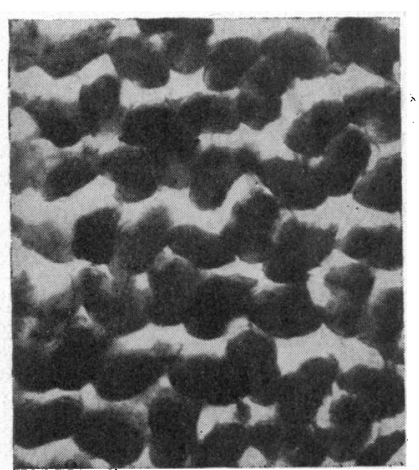

FIG. 4.

Transverse section through the ellipsoids.

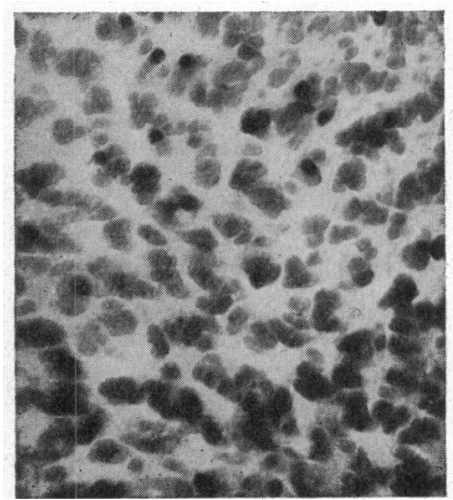

FIG. 5.

Transverse section through the outer members and pigment cells: 
conditions. Rapid fixation such as by heat or perchloride of mercury, is liable to give rise to shrinkage in the cell. Indeed I am inclined to think that better fixation is obtained by a slow fixative such as formalin and saline solution in which the eyes are kept under the conditions of light or dark adaptation as is required during the process of fixation. Osmic acid gives very good definition in regard

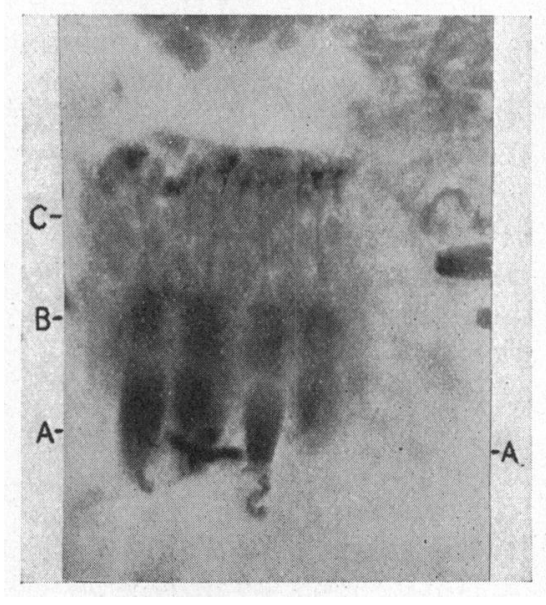

FIG. 6.

Dace, visual cells, fresh preparation treated with osmic acid (teased).
A. Myoid.
B. Ellipsoid.
c. Outer members of cells.

to the outer members, also for the examination of teased preparations (Fig. 6). Embedding makes a very considerable difference, mainly by shrinkage, to the appearance of the cell: Sections cut in paraffin are frequently useless from a histological point of view owing to the shrinkage which takes place, so that often it is not possible to tell in animals whether the outer member has a rod shape or cone shape. Transversefragmentation of this part of the cells also takes place. The outer member becomes separated from the top of the ellipsoid, leaving a pointed end to the latter which has been mistaken for a cone (Figs. 7, 8, 9 and 10). Celloidin gives the best results, as comparatively little shrinkage occurs, and if cut sufficiently thin it is easy to recognize the details of the cells. Teased osmic acid preparations are often deformed by separation of the pigment cell layer which often pulls off with it the outer member from the ellipsoid. 


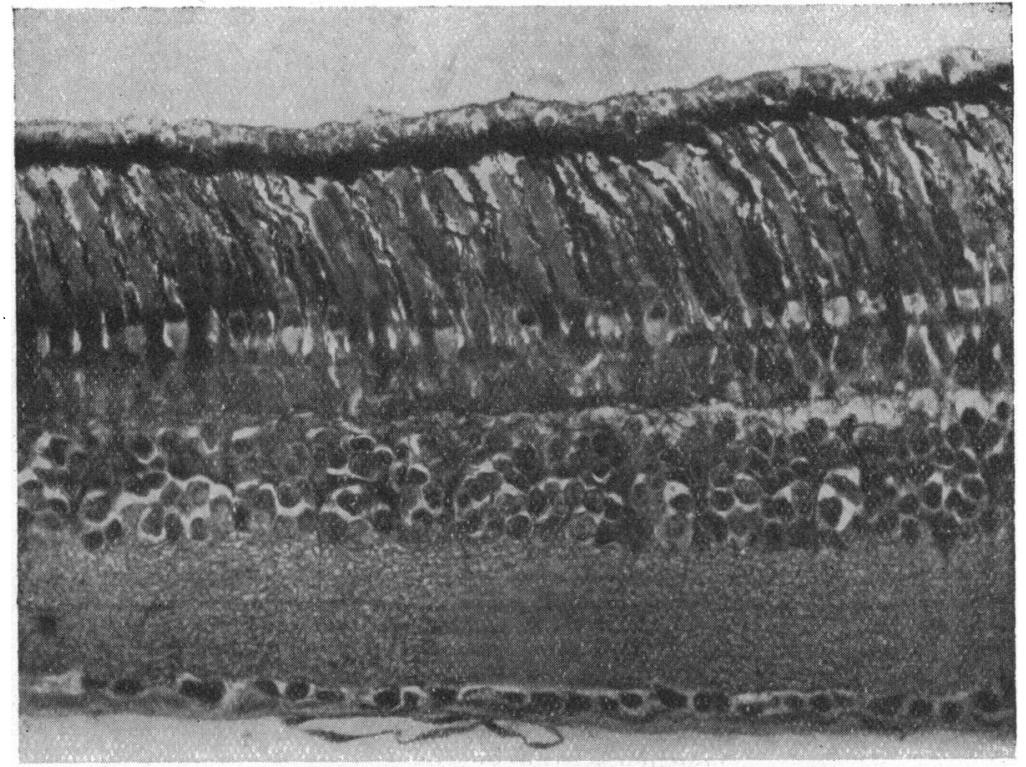

Fig. 7. Frog.

From a specimen by H. M. Bernard, osmic acid fixation, showing the rods.

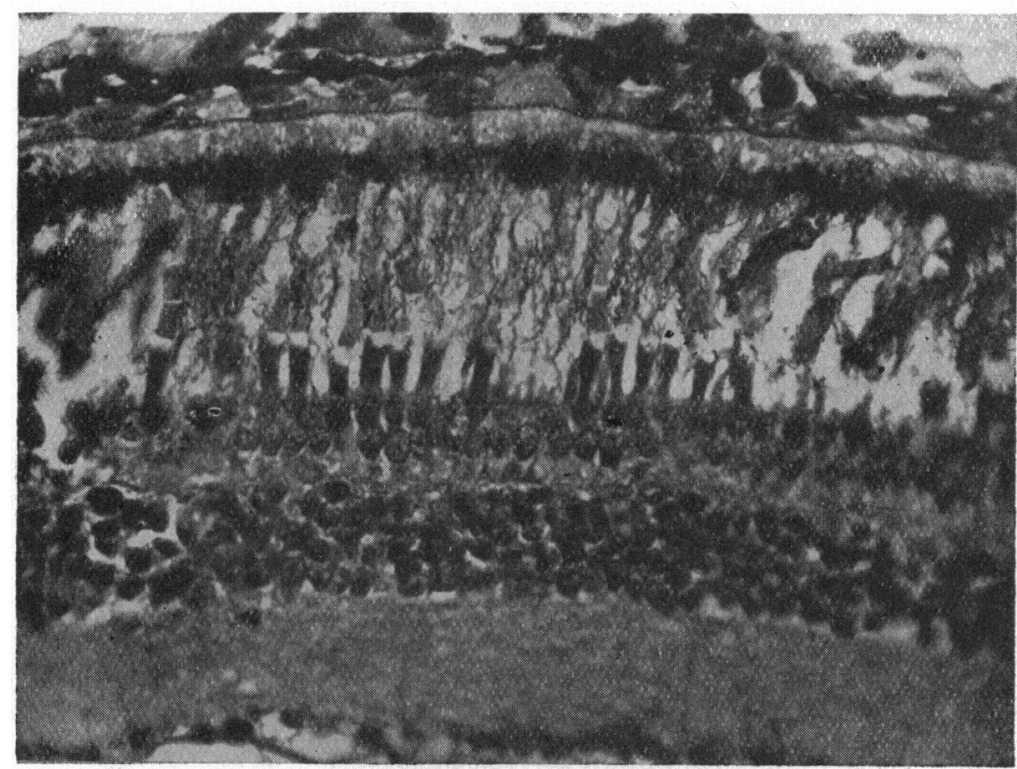

Fig. 8, FROG,

From a specimen by H.M. Bernard, perchloride fixation (paraffin section) artefact showing the breaking up of the rod outer members by shrinkage. 


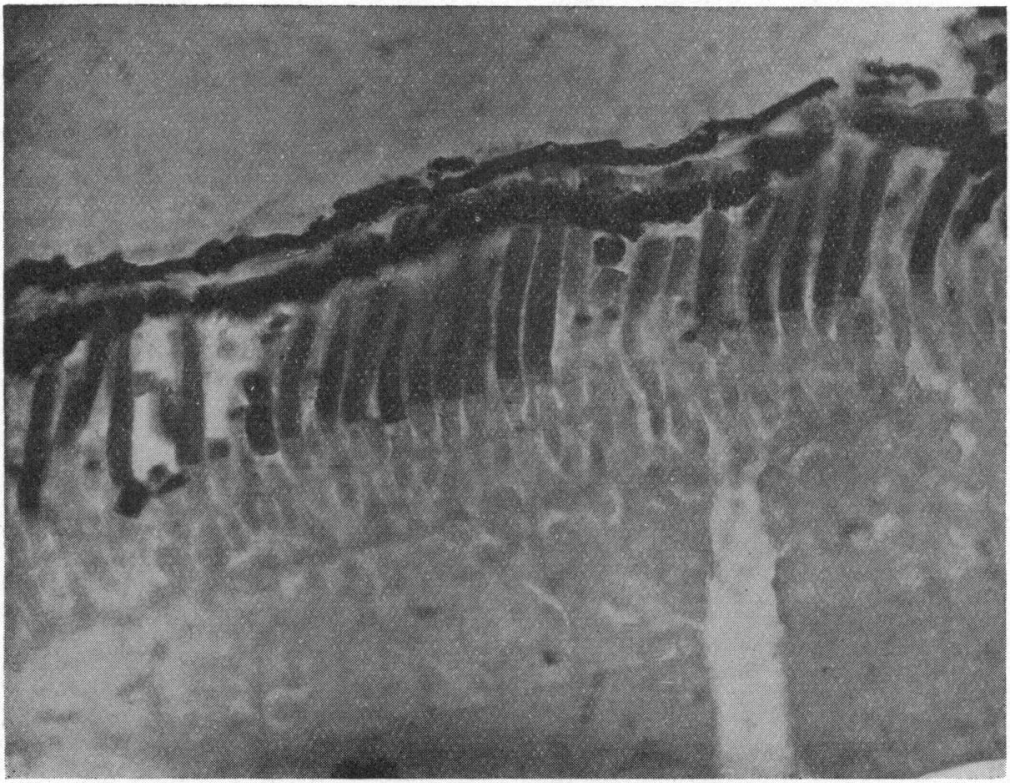

Fig. 9. Frog.

From a specimen by H. M. Bernard, osmic acid fixation. Showing rods outer members and how rods may look like cones.

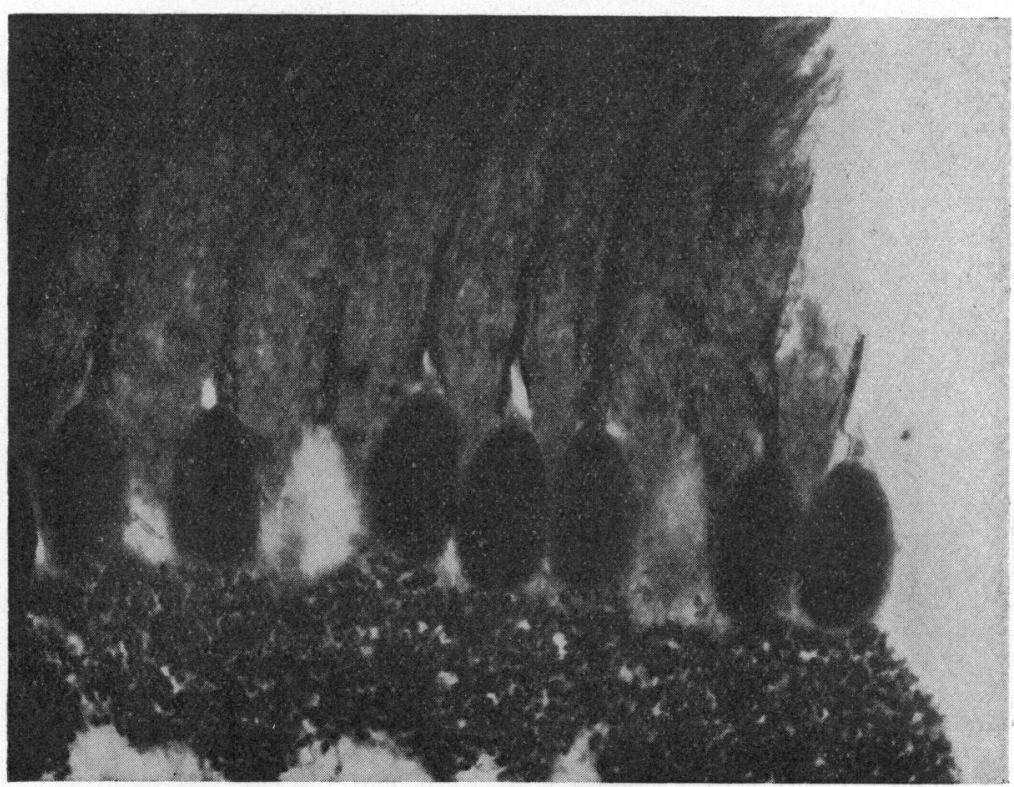

Fig. 10. Cod.

From a specimen by H. M. Bernard (paraffin section) showing the artefact of a commencing separation of the outer member from the ellipsoid. 


\section{Comparison of the Visual Cells of Fish with Man}

The retinal visual cells in fish are more than twice the size of the human retinal elements, and not packed together nearly so closely, neither does the external nuclear layer contain anything like the number of nuclei in comparison with the human retina. The chaotic condition which has arisen in comparing the histology of the visual cells in fish and man I believe is largely due to the fact

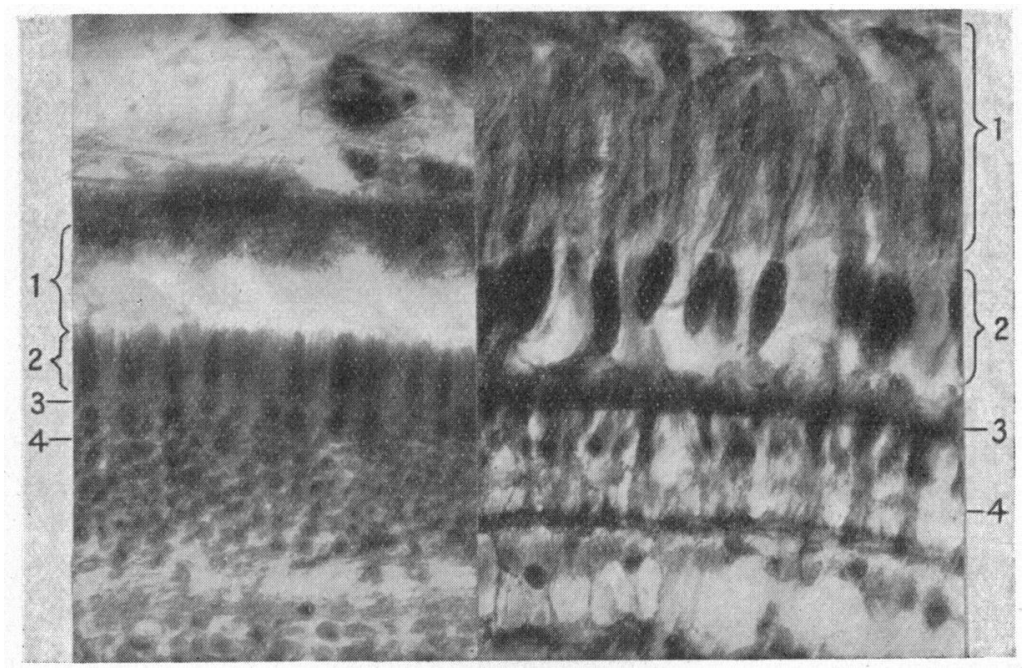

FIG. 11.
Human Retina Mallory.
$\times 420$.
Pike Mallory (4).
Bleached. $\times 420$.

Human and pike retinae prepared in the same way and photographed under the same magnifying power. The rods and cones in man are formed by the ellipsoid, the rods in the pike are designated by their outer membrane.
1. Outer members.
2. Ellipsoid and myoid.
3. External limiting membrane.
4. Nuclear layers.

that in fish the myoid and ellipsoid are similar in all the cells, whereas in man they form the rods and cones (Fig. 11). In fish on the other hand the outer member, which is little more than a bag of fluid, may take either a rod or a cone-like shape, and it is for this reason that the term rods and cones has been applied to them, whilst in the human retina the outer members are thin filaments indistinguishable in shape from each other and give no character to the cell. The visual cell therefore in the lower animals is designated as either a rod or cone on account of the shape of its outer member, whilst in the human the cell is a rod or cone

The sections show $(a)$ relative size of the visual cells in pike and man. (b) The difference in shape of the ellipsoids and myoids in mar and fish. 
according to the shape of its myoid and ellipsoid; therefore there is no true comparison between the so-called rods and cones in fish, and those of man. Whether the shape of the outer member has any influence on the future shape of the rest of the cell is extremely doubtful, and it is probably only purely a physical feature as I shall point out when speaking of the development in the lower animals. In fresh-water fish the outer members of the cell appear to be all rods if cut in celloidin, but in some paraffin sections the distortion which takes place and the angle at which some of them are cut give the appearance of a cone.

\section{The Movement of the Visual Cells}

In light adaptation (Fig. 12) part of the visual cells lying external to the limiting membrane is retracted. All the myoid and ellipsoid cells are exactly alike, and I do not believe that in this condition it is possible to distinguish any difference between the cells; they consist of a thickened myoid lying next to the external limiting membrane, with the ellipsoid intercalary disc and outer member external to it, which may have a square top (rod) or round (cone) (Fig. 13).

In dark adaptation (Fig. 14) there is an outward movement of the visual cell which is mainly due to the lengthening outwards of the

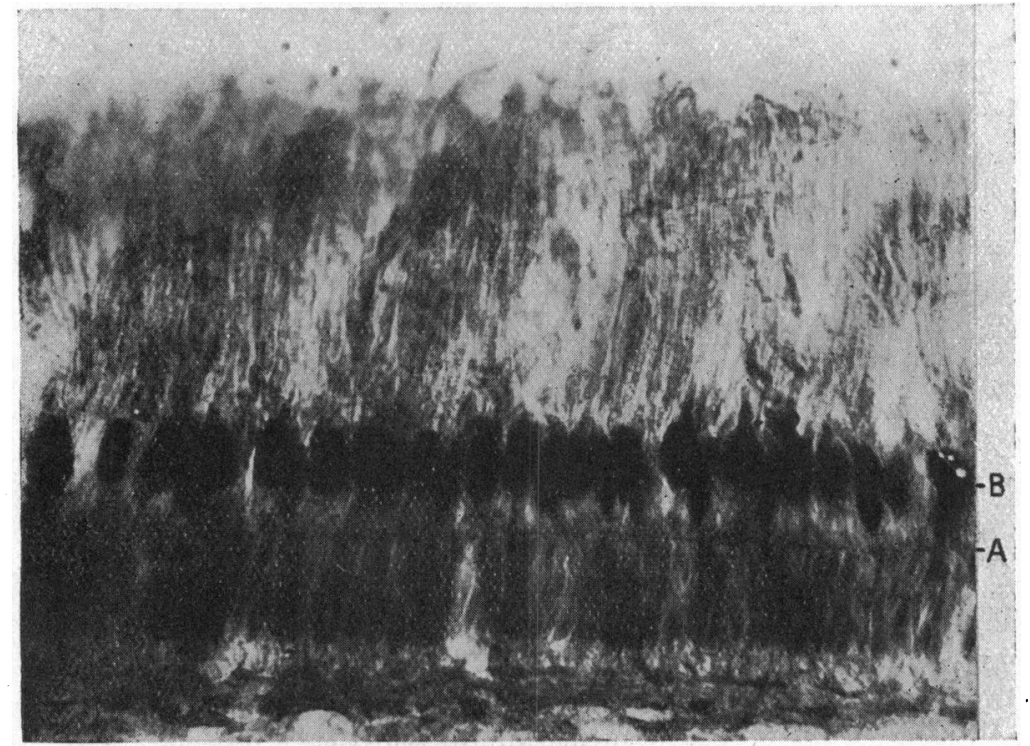

Fig. 12. (Bleached Mallory.)

Trout, light adapted, showing a retraction of the ellipsoid inwards.

A. External limiting membrane.

B. Ellipsoid retracting inwards. 
myoid; this outward lengthening may go on to such an extent as almost to draw the nucleus through the external limiting membrane. In extreme dark adaptation such as occurs in a fish which has been kept in the dark for a week, the outward lengthening of the myoid and to a large extent also of the ellipsoid leads to thinning and elongation of all the myoids and I think no distinction can be

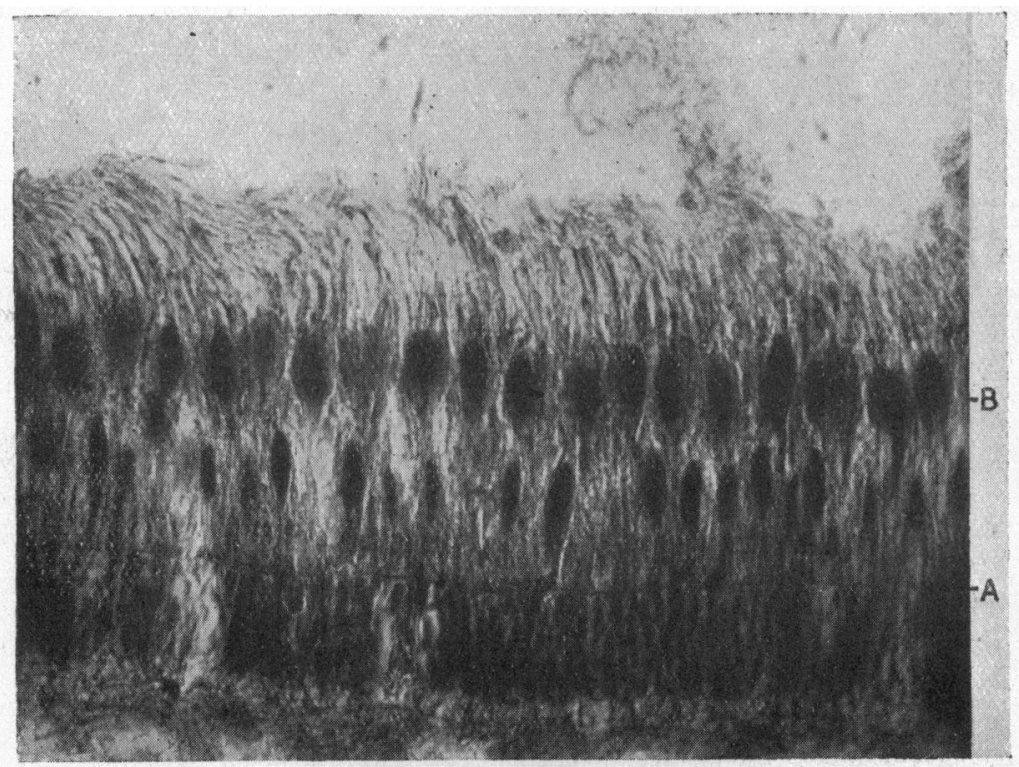

Fig. 13. (Bleached Mallory.)

Trout, dark adapted, showing movement of some of the ellipsoids outwards.

Those remaining near the limiting membrane phylogenetically may form the future cones in the human subject.

A. External limiting membrane.

B. Ellipsoids which move outwards may form future rods.

made between them (Fig. 14). In cases of partial dark adaptation (Fig. 13) such as a trout which has been kept in the dark for a couple of hours -1 to 4 hours is the time usually given for complete adaptation (Detwiler $\left.{ }^{4}\right)$, but I do not think this is sufficient, we find that about two-thirds of the ellipsoids move outwards fully and the remaining one-third only move outwards partially to about half the extent of the others and these are evenly distributed throughout the retina.

These cells whose ellipsoids do not move outwards so freely under the influence of light, I think, are the forerunners of the cones in the human subject. 


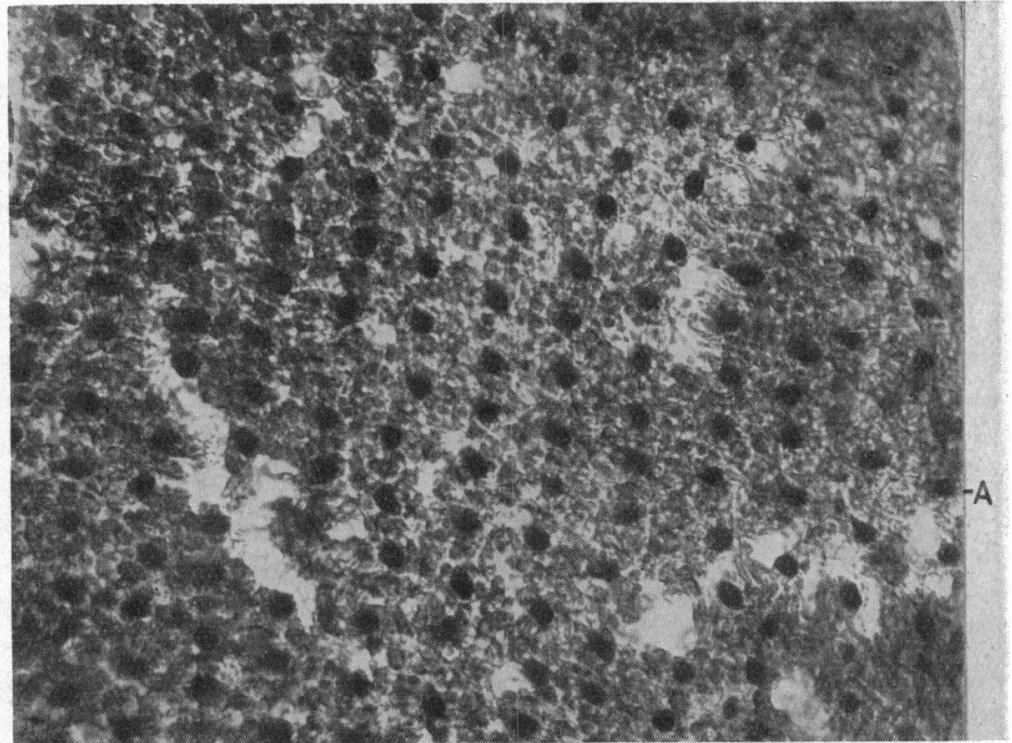

Fig. 14, Bleached Mallory.

Trout, dark adapted, tangential section, through the outer members showing the ellipsoids which have not moved outwards, and their even distribution.

$$
\text { A. Ellipsoid. }
$$

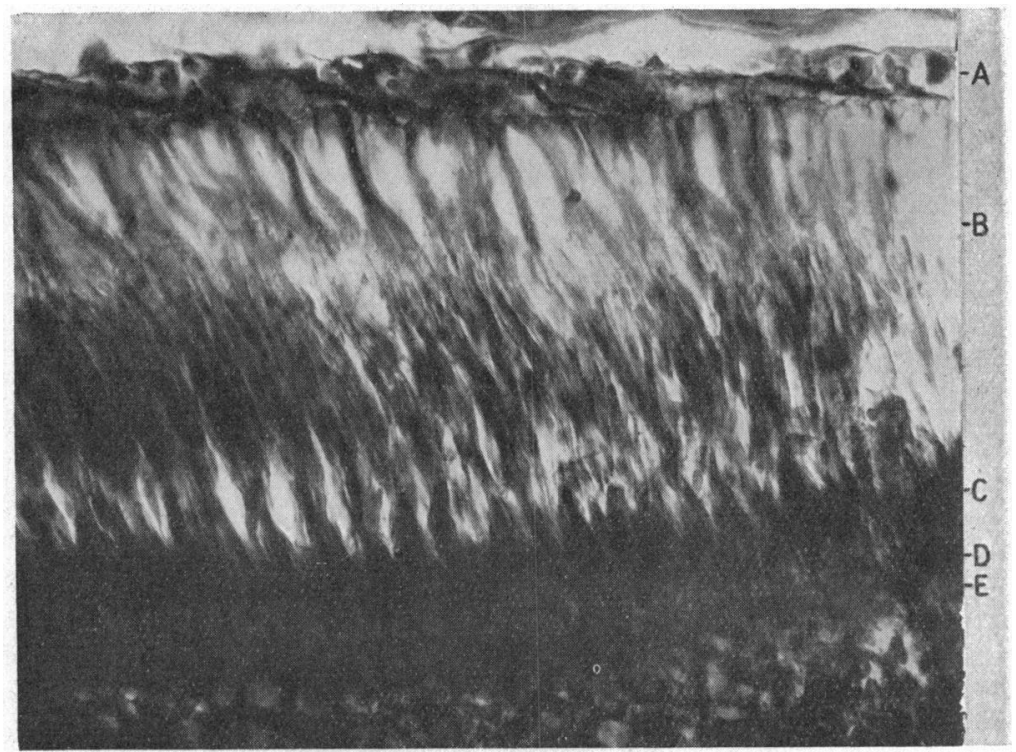

Fig. 15. (Bleached Mallory.)

Dace, visual cells under extreme dark adaptation showing the movement of the ellipsoid outwards.

The fish has been kept in the dark for three days. Showing the protrusion outward of all the ellipsoids.
A. Pigment cell layer.
B. Ellipsoid. c. Myoid.
D. External

limiting membrane. E. External limiting layer. 


\section{Development}

Cameron $^{5}$ and Bernard ${ }^{6}$ working independently came to the same conclusions with regard to the development of the outer members in the lower vertebrates and in fish. In them the visual cells always develop primarily as cones, that is to say the outer members are cone shaped. These cones are subsequently transformed into rods as they grow up against the outer layer of the optic vesicle. New visual cells growing up through the external limiting membrane between those already formed are always cones. The last developed cell has its nucleus in the outer nuclear layer furthest away from the external limiting membrane. In the fully developed retina the outer members of the visual cells are not always rods; in birds for instance they are cones and also in some fishes. I believe that the mixture of rod and cone retina is much more uncommon than is usually supposed; certainly in the fish which I have examined the cells are all rods or all cones. The mixture frequently described I believe is mainly due to artefacts in the preparation of the specimen. In development whether they remain as cones or are transformed into rods seems largely to depend on the downgrowth of the pigment cells of the outer layer of the optic vesicle moulding them into shape. In the phylogenetic development of the eye there is a considerable increase in the antero-posterior diameter of the globe, associated with this is a stretching and thinning of the retina as is evidenced by the development of the ora serrata and the decrease in thickness of the retina. At the same time there is a considerable packing together of the visual cells as their number is increased in association with the requirements of the animal for better vision. This packing together of the cells I believe causes the changes in shape of the myoid and ellipsoid into the rods and cones as found in the human retina. In fish the ellipsoids and myoids which do not move outwards under dark adaptation have more room for expansion and probably are the forerunners of the cones in the human retina. The rods, being represented by the myoids and ellipsoids of the cells which move outwards in dark adaptation are more attenuated. Cameron says: "that the fovea centralis only contains cones because in this cup-shaped region the early cone-shaped elements grow into a concavity and from this cause are compelled to remain of this shape, and in elaborating any theory regarding the difference in function of the rods and cones merely on account of their shape this fact ought not to be disregarded."

That packing together is important in the alteration of the shape in the myoid and ellipsoid in the human retina is also shown by the fact that when the cones become tightly packed together in the human macular region, they tend to resume the shape of a rod.

Of the prolongation of the visual cells which pass to the synapses 
of the bipolar cells I have made no mention. The points which I have tried to bring out in this paper are

(1) the value of Mallory's differential connective tissue stain for examining the retina;

(2) the histology of the visual cells in pike, dace, roach and trout;

(3) that there is no true comparison between the rods and cones in the lower animals and man;

(4) that the rods and cones in the human subject are phylogenetically developed from the myoid and ellipsoid in the lower animals;

(5) that the packing together of the visual elements plays a great part in changing the shape of the visual cells.

\section{REFERENCES}

1. Airey, L. B.-Jl. of Comp. Neurol. and Psychol., Vol. XXV, 1915, Vol. XXX, p. 343, 1918.

2. Jl. of Comp. Neurol. and Psychol., Vol. CXCVI, p. 121.

3. Mayou, M. S.-Brit. Jl. of Ophthal., p. 227, April, 1932.

4. Detwiler, S. R.-Jl. of Comp. Neurol. and Psychol., p. 125, 1925.

5. - Jl. of Comp. Neurol. and Psychol., p. 458, 1924.

6. Smith, D. C.-Jl. of Comp. Neurol. and Psychol., Vol. XLII.

7. Cameron, John.-Jl. of Anat. and Physiol., Vol. , p. 45.

8. Bernard, H. M.-Quart. Jl. of Micros. Scien., Vols. XLIII and XLVII.

\section{ANNOTATION}

\section{The Treacher Collins Memorial Fund}

A scheme is on foot to perpetuate the memory of Edward Treacher Collins in the rebuilding of the Pathological Department at the Royal London Ophthalmic Hospital, which will be named "The Treacher Collins" Pathological Institute.

Mr. Collins's active association with Moorfields Eye Hospital lasted nearly half - a-century. It is patent that the proposed Pathological Institute is one that would have made a profound appeal to him, and no words of ours are needed to endorse the proposal.

In spite of the critical time through which the world is passing, which has involved all of us in what the Cranford ladies called an "elegant economy," it is to be hoped that the response to this appeal will be both generous and immediate. Moorfields' sons are scattered all over the earth. We are convinced that the majority have a warm regard for their ophthalmological Alma Mater; we 